\author{
Military Technical College \\ Kobry El-Kobbah, \\ Cairo, Egypt.
}

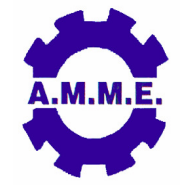

\title{
A LABSCALE HYBRID ROCKET MOTOR IGNITION SYSTEM
}

\author{
A. E. Makled*, H. E. Mostafa*, M. A. Al-Sanabawy* and M. J. Al-Timimi**
}

\begin{abstract}
The hybrid propulsion has the superiority of safety (Non-explosive), simplicity (high reliability), low environmental pollution and available technology over traditional solid and liquid propulsion, all these benefits have a tendency to low cost and laboratory work. Classical hybrid rocket motor (HRM), however have suffered from slow fuel regression rate, relatively poor combustion efficiency and still in search of safety ignition system.
\end{abstract}

The direct goal of the paper is to realize a functioning test, evaluating the performance of a designed Small-Scale Hybrid Rocket Motor (SSHRM) and prepared for laboratory firing tests. Moreover, the objective is extended to examine different types of ignition methods (pyrotechnic charge, fuse wire, heat wire and finally hot oxidizer method by using heat exchanger), which are proposed as very safe ignition method and finally recognize phenomena of re-start operation. Various fuel grains with different configuration of Polyethylene (PE), metalized $P E(P E+A L)$ and Polymethyle-methacrylate (PMMA) were developed and it is decided to use the commercial gaseous oxygen, for its availability and low cost.

A SSHRM has been designed, manufactured and tested at various conditions with high level of safety. Ignition by hot air has been proved to be a very attractive ignition method for SSHRM, for its higher safety, higher reliability and acceptable delay time.

Adding Al powder to PE fuel proved to have more smooth fuel grain surface with less plume soot, higher regression rate and combustion efficiency, less combustion instability, ignition delay time and nozzle life compared with pure PE combustion.

Finally; the re-start operation was demonstrated several times and can be carried out more easily with hot air ignition method.

\section{KEY WORDS}

Small Scale Hybrid Rocket Motor, ignition system, re-start phenomena, metal powder additive.

\footnotetext{
* Egyptian Armed forces.

** Bahrain Armed Forces.
} 


\section{INTRODUCTION}

Hybrid propulsion systems (HPS) have inherent safety and operational features that make them attractive choices for a broad range of applications, including primary propulsion for launch vehicles, upper stage propulsion, and tactical and strategic missile system [1]. In addition, the emerging field of commercial space transportation.

Historically, military applications in the United States favored the storability and launch-readiness capabilities of solid propulsion, while high specific impulse and controllability made liquid propulsion, the system of choice for civil applications. Nevertheless, recent and growing emphasis on greater propulsion safety, reduced development and recurring costs, insensitive munitions, environmentally- benign propellant, propulsion system robustness and reliability, and high degree of operability have heightened interest in hybrid propulsion for commercial space application and military propulsion programs. In response, a number of government laboratories, large industrial companies, academic research institution and small businesses have implemented hybrid rocket research and development efforts that have, with the past decade, led to significant state-of-the-art advancements in HPS. Equally important is the ongoing international interests in hybrids in France, Germany, Italy, Israel, Turkey, India, China, Japan, and other countries [2, 3, 4, 5].

HPS is the type of chemical propulsion systems, that employs propellant ingredients physically separated and by phase, this is the major source of safety.

The classical hybrid propulsion system is consisting of an inert solid fuel grain with the injection of oxidizer (gas or liquid) in the head-end of the motor. For HRM, the combustion of solid fuel is controlled mainly by the supply rate of the oxidizer to the combustion chamber. A simplified schematic-diagram of classical hybrid rocket propulsion is given in Figure (1) and other versions (pan-cake, inverse and complex) are given in Figure (2). HPS has many advantages over the conventional solid- and liquid-propulsion systems, especially in view of the recent growing emphases on enhanced safety, low component development cost, minimum environmental impact, on-off operational capability and greater controllability for rocket motors.

The fluid dynamic and combustion processes in the HRM are characterized by complex interactions between numerous physical phenomena, taking place simultaneously in the combustion chamber. These complex interactions can include solid-fuel pyrolysis, oxidizer atomization and vaporization, gas-phase diffusion, mixing, reaction and combustion, turbulent flow with mass addition, convective and radiative heat transfer, and varying fuel grain port configuration. The solid fuel regression rate, which is a very important design and performance parameter, is strongly affected by the operating conditions and/or the propellant combination and ingredient.

\section{OBJECTIVES OF THE EXPERIMENTAL WORK}

The first phase of study is designed to demonstrate the functioning of a simple hybrid 


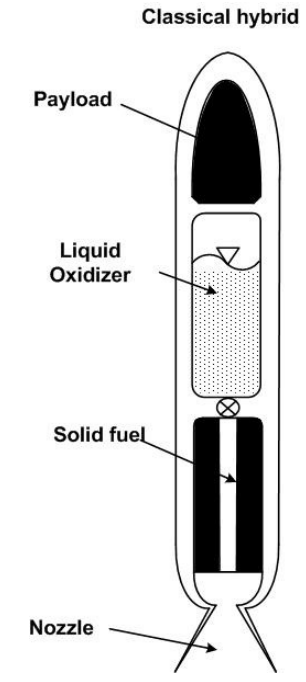

Fig. (1) Classical Hybrid Propulsion.

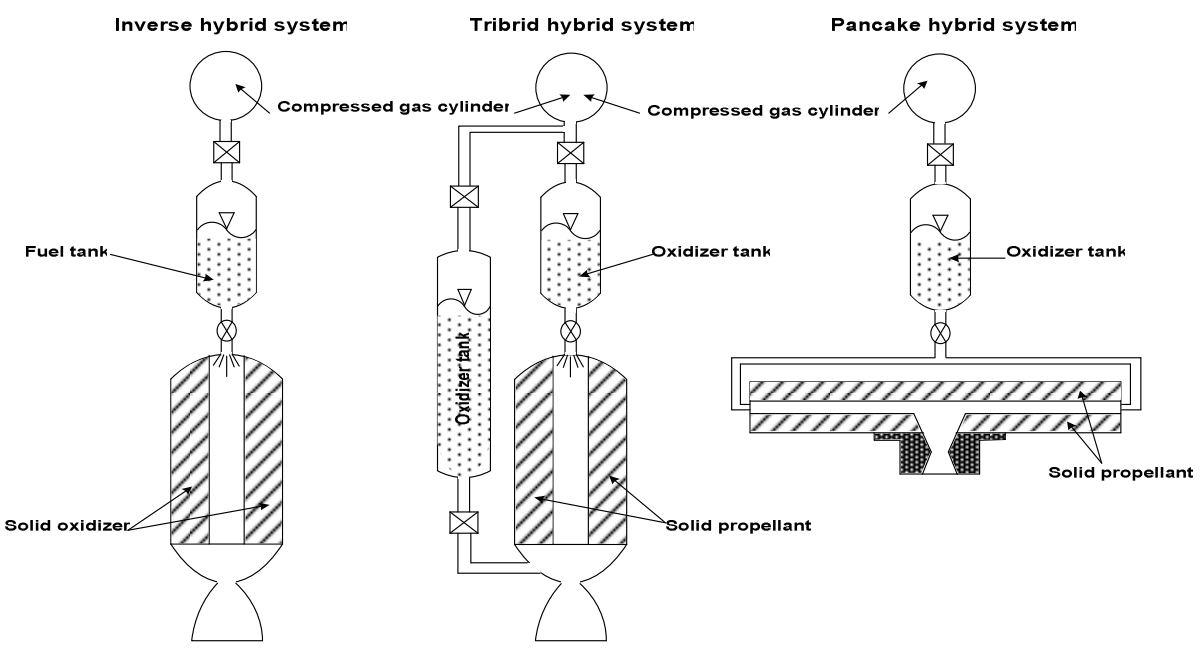

Fig. (2) Types of Hybrid Propulsion System.

test motor. In subsequent phases, test HRM's are designed, manufactured, inspected, cold tested, and prepared for laboratory firing tests for examine different types of ignition methods (pyrotechnic charge, fuse wire, heat wire and finally hot oxidizer method by using heat exchanger), which are proposed as very safe ignition method. Moreover; the objective is extended to study re-start phenomena. Measurements and data processing are performed during these tests, allowing detailed investigations and analyses.

\section{DESIGN PARAMETERS AND MANUFACTURE OF SSHRM}

\section{Design Parameters}

The ratio between the combustion chamber pressure, $P_{c}$ and the nozzle-exit pressure, $P_{e x}$ is an important parameter as it determines the expansion of the combustion gases. 
The value of the specific heat ratio, $\gamma$ is approximately 1.2-1.4 for all of the (PMMA), $(\mathrm{PE}),(\mathrm{PE}+\mathrm{Al})+\mathrm{O}_{2}$ propellants combustion gases, according to the thermo-chemical calculations [6],. The critical pressure ratio across the exit nozzle required to maintain sonic flow at the throat is given by:

$$
\frac{P_{c}}{P_{a}}=\left(\frac{\gamma+1}{2}\right)^{\frac{\gamma}{\gamma-1}}
$$

For $\gamma=1.2-1.4$, the value of this ratio is over 1.77 , giving chamber operating pressure about 2 bar for standard conditions. The lowest experimental mean pressure ratio was 2 with a sinusoidal variation of 0.15 . Therefore, the observed behavior cannot be attributed to an unsteady choking and un-choking of the nozzle.

For choosing the mixture ratio, $\mathrm{O} / \mathrm{F}$ and the given $\mathrm{P}_{\mathrm{c}}$, the corresponding theoretical characteristic velocity, $\mathrm{C}_{\mathrm{th}}^{*}$ is obtained by thermo chemical calculation as [6]:

$$
\mathrm{C}_{\mathrm{th}}^{*}=\frac{\sqrt{\mathrm{RT}_{\mathrm{c}}}}{\Gamma}
$$

where: $\quad \Gamma=\sqrt{\gamma}\left(\frac{2}{\gamma+1}\right)^{\frac{\gamma+1}{2(\gamma-1)}}$

A value of the operating pressure, $P_{c}$ is calculated with the help of the experimental combustion efficiency $\eta_{c}$ (over $90 \%$ ) as:

$$
P_{c}=\frac{C^{*} \dot{m}_{\text {tot }}}{\eta_{c} A_{t h}}
$$

where: $\dot{\mathrm{m}}_{\text {tot }}$ is the total mass flow rate of oxidizer $\dot{\mathrm{m}}_{\mathrm{Ox}}$ and fuel $\dot{\mathrm{m}}_{\mathrm{fu}}$

It is possible to estimate thrust and other performance parameters as:

The nozzle area ratio is $\frac{\mathrm{A}_{\mathrm{th}}}{\mathrm{A}_{\mathrm{e}}}=\left(\frac{\gamma+1}{2}\right)^{\frac{1}{\gamma-1}}\left(\frac{\mathrm{P}_{\mathrm{e}}}{\mathrm{P}_{\mathrm{c}}}\right)^{\frac{1}{\gamma}}\left[\frac{\gamma+1}{\gamma-1}\left(1-\left(\frac{\mathrm{P}_{\mathrm{e}}}{\mathrm{P}_{\mathrm{c}}}\right)^{\frac{\gamma-1}{\gamma}}\right)\right]^{\frac{1}{2}}$

The thrust coefficient is $\quad \mathrm{C}_{\mathrm{f}}=\left[\frac{2 \gamma^{2}}{\gamma-1}\left(\frac{2}{\gamma+1}\right)^{\frac{\gamma+1}{\gamma-1}}\left[1-\left(\frac{\mathrm{P}_{\mathrm{e}}}{\mathrm{P}_{\mathrm{c}}}\right)^{\frac{\gamma-1}{\gamma}}\right]^{\frac{1}{2}}+\frac{\mathrm{P}_{\mathrm{e}}-\mathrm{P}_{\mathrm{a}}}{\mathrm{P}_{\mathrm{c}}} \frac{\mathrm{A}_{\mathrm{e}}}{\mathrm{A}_{\mathrm{th}}}\right]$

And the thrust is

$$
\mathrm{F}=\mathrm{C}_{\mathrm{f}} \mathrm{A}_{\mathrm{th}} \mathrm{P}_{\mathrm{c}}
$$

The specific impulse is then $\quad \mathrm{I}_{\mathrm{sp}}=\frac{\mathrm{F}}{\dot{\mathrm{m}}_{\mathrm{tot}}}$ 


\section{Stochiometric Mixture Ratio}

Depending on the nature of the propellant, the combustion products will be in the form of molecules $\left(\mathrm{CO}_{2}, \mathrm{CO}, \mathrm{H}_{2} \mathrm{O}, \ldots.\right)$, free radicals $(\mathrm{C}, \mathrm{H}, \mathrm{O}, \mathrm{CO}, \mathrm{HO}$...). If the temperature exceeds $5000 \mathrm{~K}$, ionized particles will occur [7].

Calculation of the stochiometric $\mathrm{O} / \mathrm{F}$ is made by assuming that:

1) All the PE or PMMA particles are completely burned by gaseous oxygen (GO2).

2) Combustion products contain mainly $\mathrm{CO}_{2}$ and $\mathrm{H}_{2} \mathrm{O}$.

The proposed combustion equation for PE and PMMA fuel grain takes the form:

$$
\begin{aligned}
& \text { (PE) } \mathrm{C}_{2} \mathrm{H}_{4}+3 \mathrm{O}_{2}+\Rightarrow 2 \mathrm{CO}_{2}+2 \mathrm{H}_{2} \mathrm{O} \\
& \text { (PMMA) } \mathrm{C}_{5} \mathrm{H}_{8} \mathrm{O}_{2}+6 \mathrm{O}_{2} \Rightarrow 5 \mathrm{CO}_{2}+4 \mathrm{H}_{2} \mathrm{O}
\end{aligned}
$$

The stochiometric O/F is obtained by dividing the oxidizer mass by the fuel mass in this equation. Namely:

For $\mathrm{PE}(\mathrm{O} / \mathrm{F})_{\text {stochiomeric }}=3.42857$, and $\operatorname{PMMA}(\mathrm{O} / \mathrm{F})_{\text {stochiomeric }}=1.92$

\section{SSHRM Manufacture}

The SSHRM is constructed to demonstrate the concept of hybrid propulsion using off-the shelf GO2 as oxidizer, PE, PMMA as solid fuel and Al powder as metal powder additives. Before starting the design of SSHRM, it is essential to produce a detailed list of requirements. The following considerations are taken into account in the present work:

1) The SSHRM should be compatible with the available test facility, the chamber pressure level not more than 15 bar (for safety).

2) Simple design with rapid turnaround during firings.

3) Flexible design to allow different fuel grain sizes, ignition methods, nozzle shape and oxidizer flow rates up to $14 \mathrm{gm} / \mathrm{s}$.

4) Health and safety regulations (for indoor test laboratory).

5) Use of a standard commercial GO2 cylinder as oxidizer supply and the fuel charge to be manufactured by simple machining of the stock materials (PE or $\mathrm{PE}+\mathrm{Al}$ or PMMA).

\section{Characteristics of the tested hybrid motor}

The schematic SSHRM shown in Figure (3) consists mainly of the two stainless steel flanges, four screw bolts with 8 nuts, fuel grain, nozzle section and injection plate. Design characteristics are summarized in Table (1).

The SSHRM can be easily connected to oxidizer gas supply system through a 5meter rubber hose for easy handling. In addition, the tube serve as a safety precaution, since the oxidizer supply will be interrupted at any combustion flame feedback. 


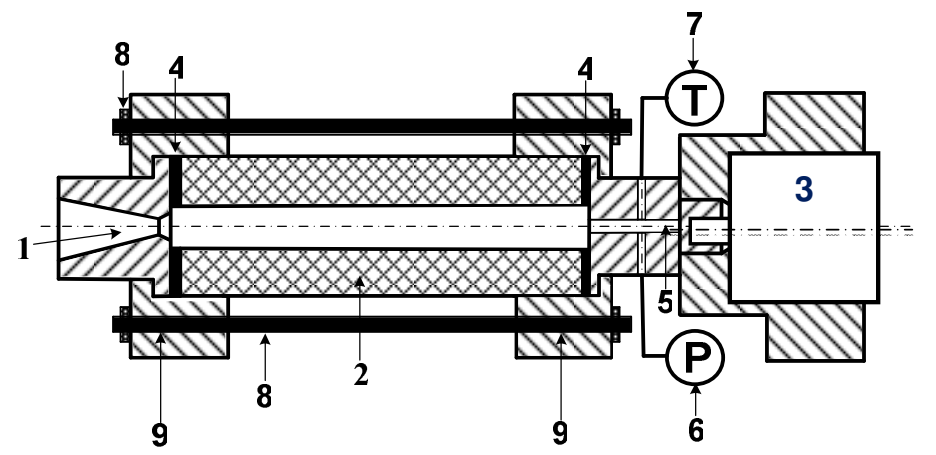

1-Nozzle port

2- Fuel grain

3- Pre-heating chamber

4- Insulation (Teflon or asbestos) disc

5- Oxidizer inlet

6- Pressure transducer connector

7- Temperature thermocouple connector

8- Screw bolts with nuts

9- Stainless steel flange

Fig. (3) The Schematic of Small-Scale Hybrid Rocket Motor.

Table (1) Small-Scale Hybrid Rocket Motor Design Parameters.

\begin{tabular}{|l|c|}
\hline Parameter & Value \\
\hline Maximum regulator pressure(bar) & 15 \\
Oxidizer flow rate (gm/s) & Up to 14 \\
Initial fuel grain port diameter (mm) & 5 to 30 \\
Final fuel grain port diameter (mm) & 50 \\
Fuel grain length (mm) & 30 to 150 \\
Mean regression rate (mm/s) & Up to 1.0 \\
Injection pressure (bar) & Less than 15 \\
Oxidizer tank pressure (bar) & 30 to 100 \\
Maximum ignition pressure (bar) & 25 \\
Maximum chamber pressure (bar) [MEOP] & 30 \\
Burning time (s) & Less than 20 \\
Nozzle throat diameter (mm) & 3 up to 6 \\
Expansion ratio & 10 up to 15 \\
Mixture ratio (O/F) & 2 to 10 \\
Combustion efficiency & about $90 \%$ \\
\hline
\end{tabular}

\section{Combustion chamber and fuel grain}

The combustion chamber is constructed as fuel grain channel with 5 to $28 \mathrm{~mm}$ diameters, with two end insulation asbestos or Teflon gasket $50 \mathrm{~mm}$ diameter with 3 $\mathrm{mm}$ thickness. The fuel grain channel tube is 22.5 up to $10 \mathrm{~mm}$ thick. Maximum Expected Operating Pressure [MEOP] is 30 bar.

The fuel grain material is PMMA (commercial name ACRYLIC or Plexiglas) \& Polyethylene with different Al metal powder percent $(2.5,5,7.5,10,12.5$, and $15 \%)$. The fuel grains are cylindrical with outer diameter $50 \mathrm{~mm}$.

Even though most polymers are excellent and available material as hybrid fuels, PMMA is chosen for the following reasons; cheap, available off-the-shelf in local market, easy to machine; no special tools required, transparency allows possible observation of combustion, ignition, restart phenomena and final port configuration and inert during handling, storage and machining. Table (2) shows the main characteristics of PE, Al and PMMA materials. 


\section{Injection plate}

Using a gas as an oxidizer is simpler state. The GO2 is easy for injection and measurement. Finally, the injection faceplate has been designed with a single $5 \mathrm{~mm}$ diameter central bore. The plate is fitted into pre-heating chamber end. For measuring pre-heating chamber temperature, is inserted $\mathrm{K}$ type thermocouple through $3 \mathrm{~mm}$ hole and filled by high temperature cement, and for measuring chamber pressure $3 \mathrm{~mm}$ tube is connected to pressure transducer.

Table (2) The Main Characteristics of PE, Al and PMMA Materials.

\begin{tabular}{|l|l|l|l|}
\hline Parameters & PMMA & PE & Al \\
\hline Molecular formula & $\left(\mathrm{C}_{5} \mathrm{H}_{8} \mathrm{O}_{2}\right)_{n}$ & $\left(\mathrm{C}_{2} \mathrm{H}_{4}\right)_{n}$ & $\mathrm{Al}$ \\
\hline Molecular weight(Kg/K mol) & 100.12 & 28.05 & 26.98 \\
\hline Density $\left(\mathrm{Kg} / \mathrm{m}^{3}\right)$ & 1180 & 940 & 2700 \\
\hline Melting point(k) & $433-473$ & 450 & 660 \\
\hline Heat of combustion(MJ/Kg) & 2602 & 46.4 & 10.71 \\
\hline Standard heat of formation(KJ/mol) & -430.5 & -58.6 & 0 \\
\hline
\end{tabular}

\section{Nozzle}

Since cost and simple design are always required for experimental equipment, the cheaper copper material has demonstrated to work properly for the heavy use. Taking a nozzle throat diameter of 3 and $6 \mathrm{~mm}$ gives a theoretical chamber pressure up to 15 bar. The nozzle area ratio was chosen to be 10 and 15; Figure (4) shows the different shapes of nozzle block during firing.

\section{Ignition system}

Several ignition methods have been tested investigated during experimental work. In order to provide consistent experimental results it is desirable that the ignition method is reliable, repeatable and consistent. Pyrotechnical ignition is accomplished by a small initiation charge of gun powder (black powder). Electrical ignition uses a fuse wire to generate spark or a heat wire to generate heat. Finally, by heat exchanger is used to heat the oxidizer.

\section{Oxidizer gas supply}

The choice of oxidizer could be made depending on the actual requirements of the engine. For the present work, it is decided to use the commercial GO2, for its availability and low cost. Figure (5) describes SSHRM oxidizer gas supply system. Normal industrial Oxygen gas bottles with maximum pressure 100 bar are used.

The solenoid valve and ignition spark are engaged from relay switch connected, to make sure the combustion chamber is fully developed of GO2 before ignition spark in case of pyrotechnic charge.

A copper tub of $6 \mathrm{~mm}$ outer diameter is used of the high-pressure line, and a tube from hard rubber material is used at the low-pressure line. For best sealing are Swagelok fittings.

The SSHRM system is operated from control room at atmospheric conditions $20 \pm 5$ ${ }^{\circ} \mathrm{C}$. The duration of the oxygen supply and ignition time can be adjusted from control room. 


\section{SSHRM TESTS}

\section{Static Firing Tests}

The SSHRM should pass a series of cold tests to minimize the risk of damage during firing. Cold testing (hydrostatic test) has been accomplished on the system, using high-pressure air for all fitting connectors. During that phase, the hybrid motor system assembly is tested for leakage free operation.

Silicon materials, which are good for oxidizer environments, are employed to ensure a static force seal for the HRM. The silicon was also utilized to create a static seal for the fuel grain and fuel grain support interface. A hydrostatic test is performed on the engine to assure that it could withstand at least 30 bar. The rocket motor is held at that pressure for 15 minutes without leakage or failure.

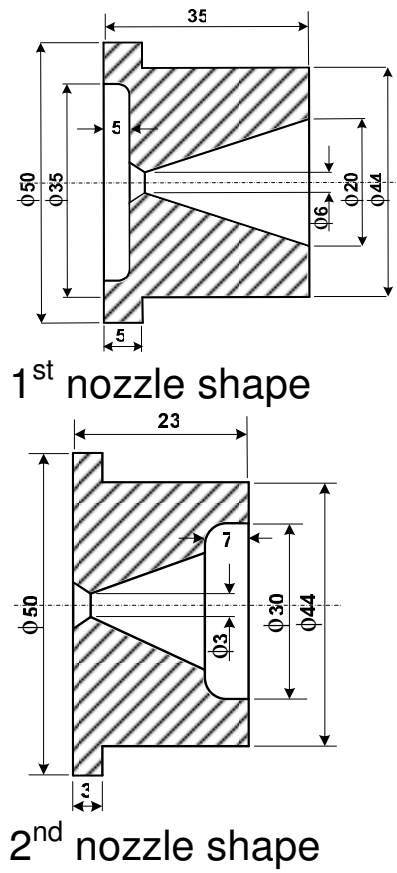

Fig. (4) HRM Nozzle Block.

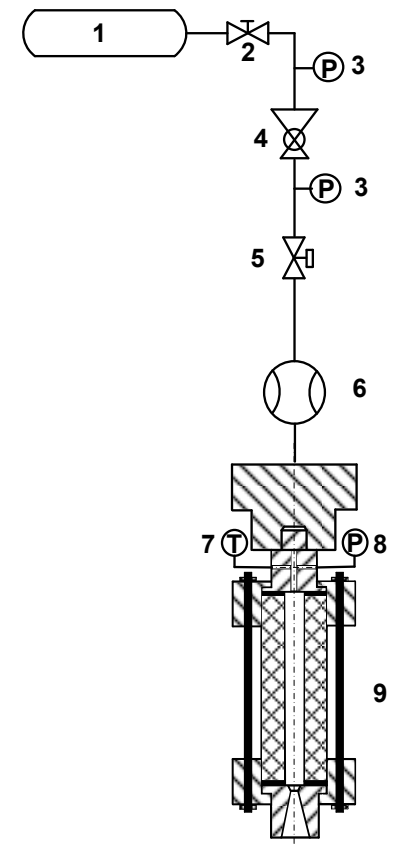

Fig. (5) Feeding System.
1- Oxidizer Tank

2- Needle Valve

3- Pressure Gage

5- On-Off Valve (Solenoid Type)

7-K Type Thermocouple

9- Hybrid Rocket Motor

4- Pressure Regulator

6- Rota-Meter

8- Pressure Transducer

\section{Function Test}

For achieving a successful firing, it is necessary to make several attempts to adjust the operational motor parameters. The adjustable parameters are, ignition current, chamber pressure, oxidizer flow rate and nozzle throat diameter. Demonstration of sample successful function tests using the simple hybrid motor using gaseous oxygen as oxidizer and different solid fuels, namely: PMMA, pure PE and PE with AI additives are given in Figure (6).

\section{Procedure of Firing Test}

The hot testing of the system is accomplished, through large number of experiments. Over 20 tests are run using GO2 with PMMA to investigate the suitable ignition method, re-start operation and over 40 tests are run using PE with different $\mathrm{Al}$ powder percentages. 


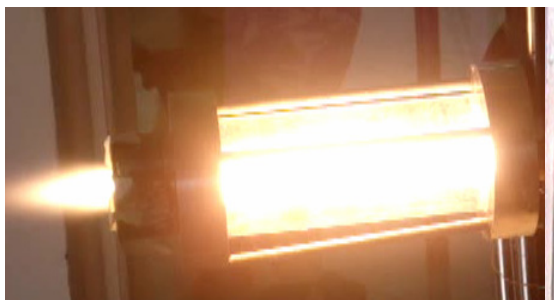

$\mathrm{PMMA}+\mathrm{GO}_{2}$ Firing

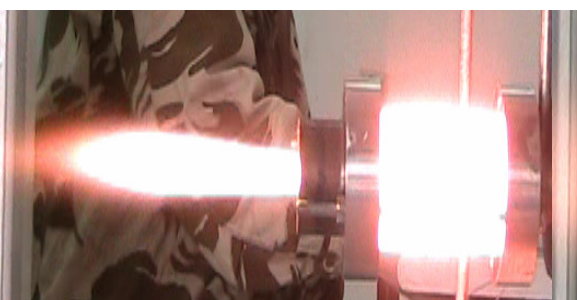

$\mathrm{PE}+\mathrm{GO}_{2}$ Firing

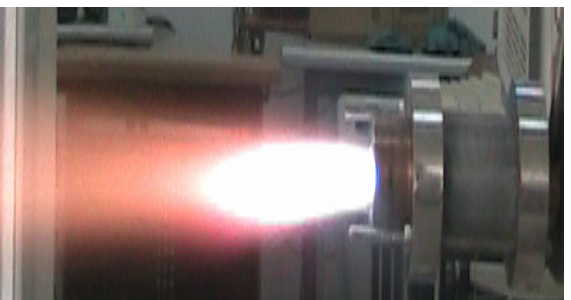

$\mathrm{PE}+\mathrm{Al}+\mathrm{GO}_{2}$ Firing

Fig. (6) Sample Function Tests.

The system allows the measuring of pressures at the feed line, oxygen tank, preheating chamber; GO2 flow rates; and temperature in the preheating chamber during the test run.

In addition, other variables are measured before and after a test run, ambient temperature, and nozzle throat diameter, mass of the fuel grain using digital balance. The laboratory test facility comprises two parts:

1) Test stand zone (test bed, camera, feeding system and safety area).

2) Control room (computer system, recording data accession (DMC plus program), and calibration instrumentations for pressure transducer and temperature thermocouple).

Layout of the test facility is shown in Figure (7) and the recorded data of pressure and temperature by data accession (DMC plus program) are shown in Figure (8).

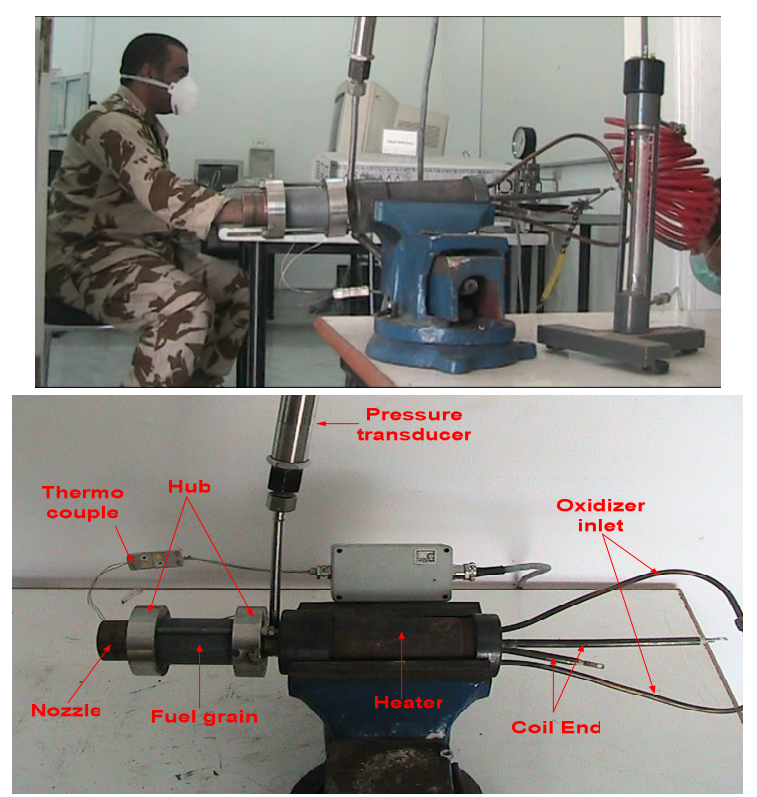

Fig. (7) Laboratory Test Facility.

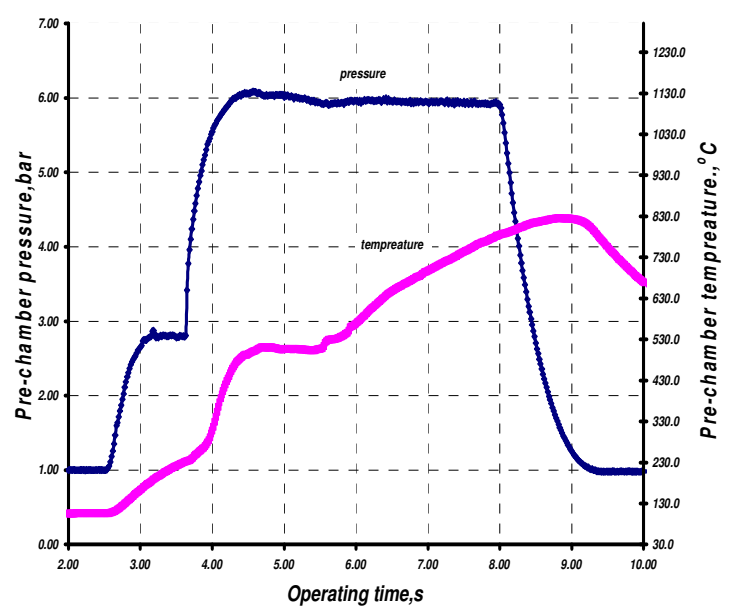

Fig. (8) Experimental Pressure and Temperature with Operating Time.

The important events during the tests are given as:

1) Adjust the power to be on, the data acquisition system (DMC plus program) for measuring pressure and temperature and recording video camera.

2) Check if sufficient gas is available in the oxygen compressed gas cylinder (GPA). 
3) Fuel grain sample weight is measured before the firing, length and inner diameter active port are measured.

4) Assembly of HRM system (fuel grain, bolts connection, nozzle, front and rear flanges), measuring instruments (pressure transducers and thermo couple connection, rato-meter, pressure gages) and the SSRM is mounting on test stand.

5) Select and connect active channels, in data acquisition system to measure temperature and pressure respectively.

6) Run calibration program implemented in the data acquisition system (DMC plus program), to measure pressure and temperature in the preheating chamber. Adjust the screen to read sample rate of $60 \mathrm{read} / \mathrm{s}$ and store the output file data. Be placed on the mouse button to start. (Standby).

7) Adjust feeding system (regulator valve output pressure, oxidizer mass flow rate, solenoid check out, pressure and temperature instruments reading).

8) Heater is connected to the power source (turn on) until to reach the required temperature.

9) Ready to start firing and measurement, run the video camera to record the firing, turn off the heater power, press start data acquisition system (DMC plus program), count down to zero, solenoid opened, enter the hot gas lead to start firing, stop firing is achieved by turning of the solenoid valve, the exact time of firing is recorded using a stopwatch, stop the data acquisition system (DMC plus program), camera, and GPA regulator valve.

10) After the completion of firing, the weight and the inner diameter of the fuel grain sample are measured and discharge oxygen gas from feed system.

11) Go to step two for the next test.

Throughout the development and testing, the following problems were encountered:

- Fuel grain seal failures (sealing).

- Melting of the rear part of the grain and the molten material is moved backward to block the injector hole.

- Enlargement of the nozzle throat dimensions is the direct consequence of the effect of Al particles.

\section{TEST EVALUATION}

The system of measurement is proposed to measure pressure and temperature at preheating chamber. The special software program amplifier system DMC plus is employed to make analysis of the digitally measured data. This program has been adapted for the use with the hybrid motor. The program modifications are based on the following formulations.

The average operating pressure in the preheating chamber is calculated as:

$$
\bar{P}_{a v}=\frac{\int_{t_{1}}^{t_{2}} P_{c}(t) d t}{t_{b u}}
$$

The average fuel mass flow is determined according to 


$$
\overline{\dot{m}}_{\mathrm{fu}}=\frac{\Delta \mathrm{m}_{\mathrm{fu}}}{\mathrm{t}_{\mathrm{bu}}}
$$

where $\Delta \mathrm{m}_{\mathrm{fu}}$ is the fuel consumption, obtained by weighing the fuel grain before and after the test. The average mixture ratio O/F can be determined:

$$
\mathrm{O} / \mathrm{F}=\frac{\overline{\mathrm{m}}_{\mathrm{ox}}}{\overline{\dot{\mathrm{m}}}_{\mathrm{fu}}}
$$

The Average oxidizer, fuel and total mass fluxes during a test run are obtained as:

$$
\bar{G}_{\text {ox }}=\frac{\left\lfloor G_{o x, i}+G_{o x, f}\right\rfloor}{2} \bar{G}_{f u}=\frac{\left\lfloor G_{f u, i}+G_{f u, f}\right\rfloor}{2} \bar{G}_{\text {tot }}=\frac{\left\lfloor\bar{G}_{\text {tot }, o x}+\bar{G}_{\text {tot }, f u}\right\rfloor}{2}
$$

The average regression rate is obtained by two different methods, the $1^{\text {st }}$ method is based upon the mass loss of the fuel grain $\Delta \mathrm{m}_{\mathrm{fu}}$ and the $2^{\text {nd }}$ method is based upon the determination of the mean diameter of the channel before and after a test run. The average regression rate of the fuel is given by:

$$
\begin{gathered}
\dot{r}_{f u}=\frac{\Delta d_{p o}}{2 \Delta t_{b u}}=\frac{\sqrt{\frac{4\left(m_{f u, i}-m_{f u, f}\right)}{\pi \rho_{f u} L_{f u}}+d_{p o, i}^{2}}}{2 t_{b u}}-d_{p o, i} \\
\dot{r}_{f u}=\frac{d_{p o, f}-d_{p o, i}}{2 t_{b u}}
\end{gathered}
$$

where $\rho_{\mathrm{fu}}$ is the solid fuel grain density $\mathrm{m}_{\mathrm{fu}, \mathrm{i}}$ and $\mathrm{m}_{\mathrm{fu}, \mathrm{f}}$ are the initial and final grain masses consecutively, $d_{p o, f}$ and $d_{p o, i}$ denote the final and initial grain port diameter, $t_{b u}$ is the burning time.

The experimental characteristic exhaust velocity $\mathrm{C}_{\text {exp }}^{*}$ is calculated according to:

$$
C_{\exp }^{*}=\frac{\int_{t_{1}}^{t_{2}} P_{c}(t) d t A_{t h}(t)}{\Delta m_{o x}+\Delta m_{f u}}
$$

The combustion efficiency of hybrid system $\eta_{c}$ could be calculated by comparing the average $C_{t h}^{*}$ determined by thermo-chemistry code, equation (2) and average $\mathrm{C}_{\text {exp }}^{*}$,equation (16) as in the following equation: 


$$
\eta_{\mathrm{c}}=\frac{\mathrm{C}_{\mathrm{exp}}^{*}}{\mathrm{C}_{\mathrm{th}}^{*}}
$$

Sample results from static firing tests on SSHRM are given in Table (3).

Table (3) Static Firing Results of Hybrid Motor.

\begin{tabular}{|l|l|}
\hline Initial data & Maximum Temperature $=1054.1^{\circ} \mathrm{C}$ \\
\hline Regulator pressure $=10$ bar & Burning time $=4.13 \mathrm{~s}$ \\
Throat diameter $=6 \mathrm{~mm}$ & Fuel mass consumed $=5.8 \mathrm{gm}$ \\
Measured oxidizer mass flow rate $=9.3 \mathrm{gm} / \mathrm{s}$ & Fuel grain length $=80 \mathrm{~mm}$ \\
Final port diameter $=10.9 \mathrm{~mm}$ & \\
Initial diameter $=5 \mathrm{~mm}$ & \\
\hline Calculated data & \\
\hline Ignition time $=0.93 \mathrm{~s}$ & \\
Average pressure $=5.29 \mathrm{bar}$ & \\
Fuel mass flow rate $=1.404 \mathrm{gm} / \mathrm{s}$ & \\
Mean mixture ratio $=6.62$ & $0.7143 \mathrm{~mm} / \mathrm{s}$ \\
Regression rate $(\Delta$ mass $)=0.7143 \mathrm{~mm} / \mathrm{s}$ \\
Regression rate $(\Delta$ diameter $)=0.714 \mathrm{~m} / \mathrm{s}$ \\
Experimental characteristic velocity $=1397.3 \mathrm{~m}$ \\
Theoretical characteristic velocity $=1490.8 \mathrm{~m} / \mathrm{s}$ \\
Combustion efficiency $=93.7 \%$
\end{tabular}

\section{EXPERIMENTAL HRM IGNITION METHODS}

The purpose of the current work is to investigate and select a safe and reliable method for hybrid system ignition. The basic problem of interior ballistic design of HRM is that of established ignition and steady state combustion of the fuel and oxidizer, which are at different physical states, two limiting cases occur, i.e. hypergolic and non-hypergolic ignition. The system of ignition for starting rocket motor operation should provide safe and long time storage, and absolutely reliable and rapid starting.

For a non-hypergolic fuel and oxidizer, a separate source of ignition will be needed for starting SSHRM. In a HRM, three methods of ignitions are examined and investigated:

Pyrotechnical, approach in which the ignition is accomplished by a small initiation charge of gunpowder (black powder charge); used squibs have bridge resistance of $3 \Omega$. For initiation, a minimum of 30 -volt DC, $5 \mathrm{~A}$ current is required. The flame is amplified by using $0.5 \mathrm{gm}$ black powder packed around the sensitive element.

Electrical, approach in which the ignition is accomplished by using fuse wire to generate spark or using heat wire to generate heat. The main characteristic of used fuse copper wire is $1 \mathrm{~A}$ with length about $25 \mathrm{~mm}$. The wire is inserted inside fuel grain channel close to injection head and is connected by two terminals of copper insulted wire, to supply 30-volt DC, 5 A from power supply to generate spark. 
The other method uses hot tungsten wire $0.5 \mathrm{~mm}$ diameter, to generate heat when supplied by 30 -volt DC, 5 A. That wire must be contacted to the fuel grain-burning surface.

Heat Exchanger, the ignition is accomplished by using high power coil (2000 W) placed inside the chamber. The $\mathrm{GO}_{2}$ is heated as it passes in contact with the coil. Figure (9) shows the different ignition methods used for SSHRM start.

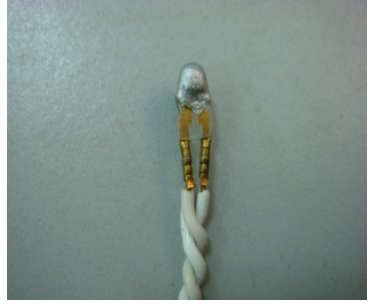

Squib assembly

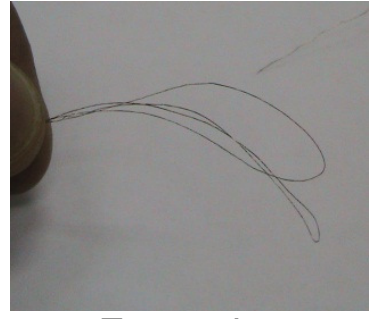

Fuse wire

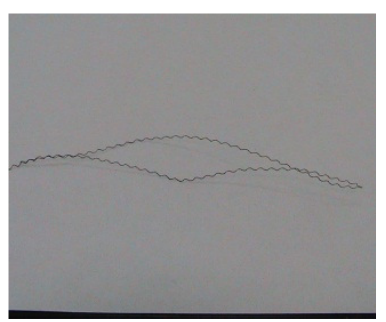

Heat wire

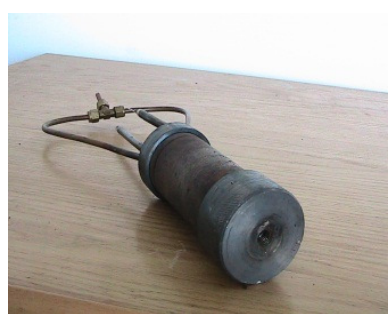

Heat exchanger

Fig. (9) Ignition Methods.

A series of experiments were carried out to investigate the indicated ignition methods. The details of experimental procedures and results will be summarized.

\section{Pyrotechnic Ignition Method}

The ignition procedure by Pyrotechnic charge in hybrid system is described in Figure (10). The procedure is summarized as follows:

- Adjust feed system.

- Open the GO2 line by solenoid valve command (ON).

- After approximately $0.25 \mathrm{~s}$, the 30 -volt DC 5A current pass through squib to produce a flame of heated gases. The initial burning surface is melted and evaporated. Vaporized gases react with the oxidizer media to start combustion. This method showed a small ignition delay time about $0.4 \mathrm{~s}$.

With a too high mass flux of oxidizer, several ignition failures occurred. The reliability increases to maximum with low oxidizer mass flux. Figure (11) describes a sample of obtained courses of pressure and temperature with time using pyrotechnic charge.

The initial pressure rise appeared in the $1^{\text {st }}$ part of P-T curve is similar to normal solid RM with acceptable minimum delay ignition time less than $0.4 \mathrm{~s}$. the longer delay of temperature rise may be attributed to the lower response of the used thermocouple.

\section{Fuse Wire (Spark) Ignition Method}

The ignition procedure by fuse wire tool with PMMA fuel grain and $\mathrm{GO}_{2}$ oxidizer is describes in Figure (12). The measurement procedure is summarized as follows:

- Adjust feed system.

- Open the GO2 line by solenoid valve command $(\mathrm{ON})$.

- After approximately $0.25 \mathrm{sec}$, the 30 -volt DC 5A current passes through the 


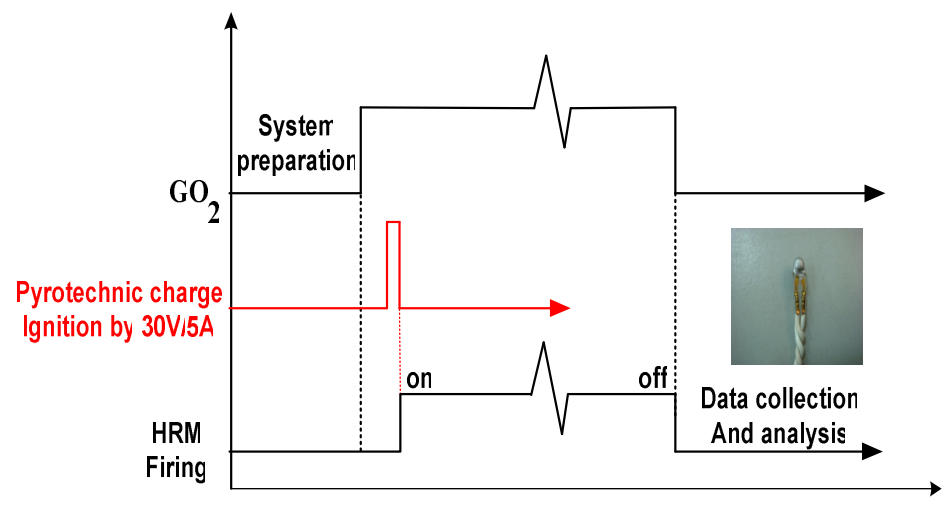

Fig. (10) Pyrotechnic Tool Ignition Procedure.

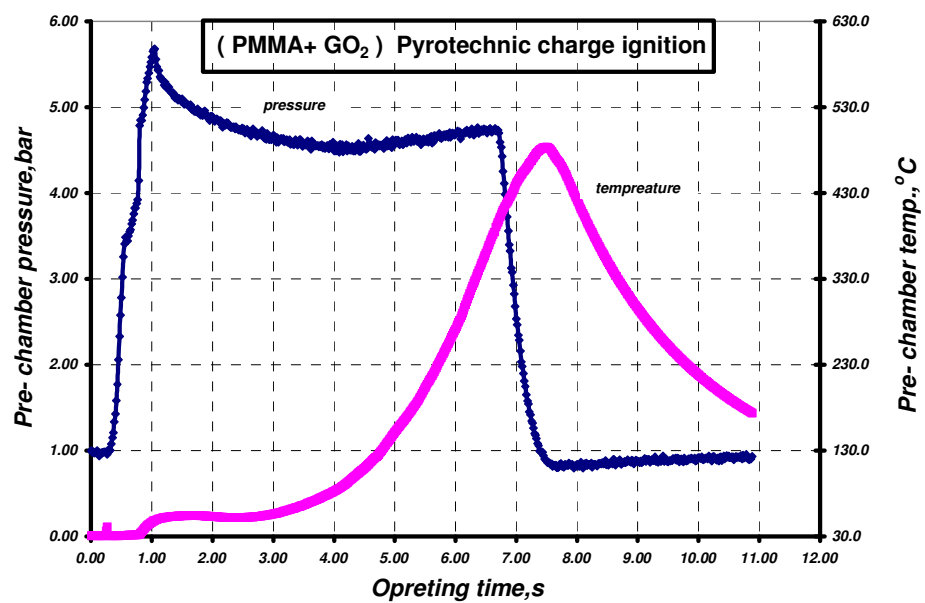

Fig. (11) Ignition by Pyrotechnic Charge.

electric fuse wire to produced spark. The burning surface near to spark spot melts, evaporates and shows a reaction of vapors with GO2occurs leading to start of ignition and combustion. That method longer delay ignition time (less than $0.75 \mathrm{~s}$ ) compared to the previous one (less than $0.4 \mathrm{~s}$ )

In some instance, the combustion is interrupted after ignition. This could be explained by too high oxidizer mass flux, which prevented adequate surface vaporization.

Figure (13) describes a sample of tested results showing of the behavior of pressure and temperature with time in case of using fuse wire method with $P M M A$ and $\mathrm{GO}_{2}$.

The fuse wire spark appeared before ignition has been established. The spark flame spread along fuel grain surface to reach steady state combustion after one second. The thermocouple at preheating chamber reached steady state chamber temperature after $6.5 \mathrm{~s}$ of firing time. 


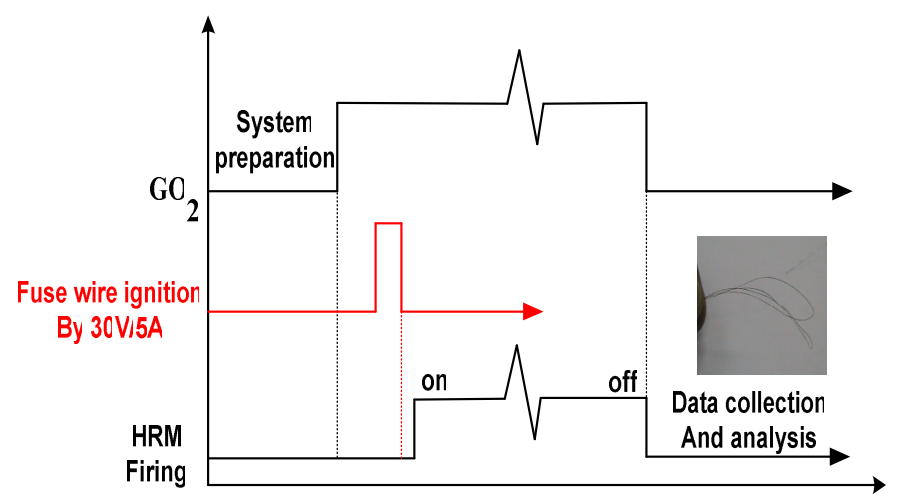

Fig. (12) Fuse Wire Tool Ignition Procedure.

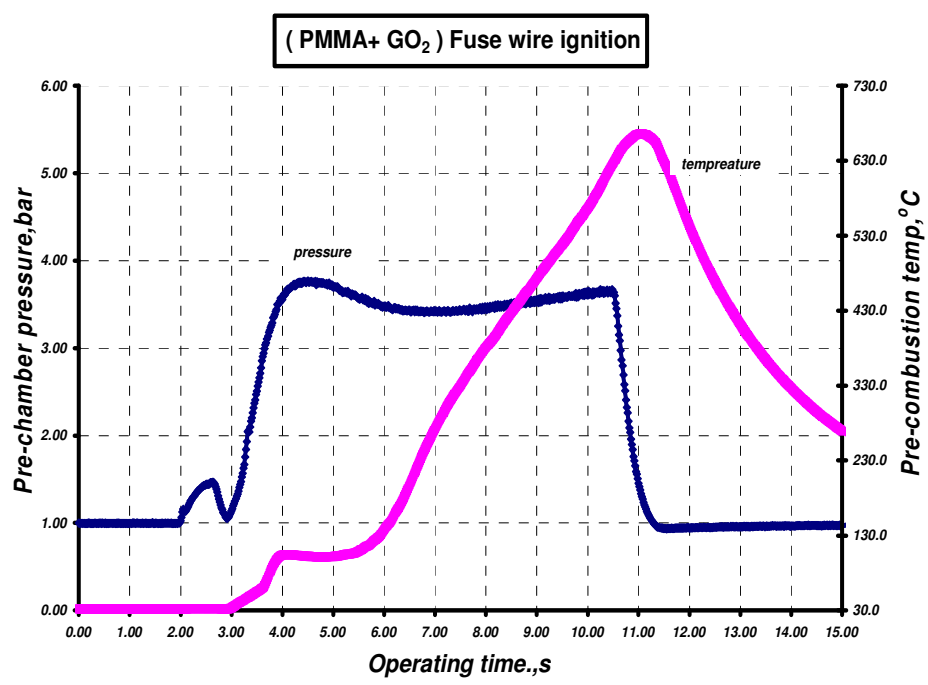

Fig. (13) Ignition by Fuse Wire.

\section{Heat Wire Ignition Method}

The ignition procedure by heat wire tool with PMMA fuel grain as transparent media and $\mathrm{GO}_{2}$ oxidizer is described in figure (14). The measurement procedure was:

- Adjust feed system.

- Passing 30-volt DC 5A current through thermal wire.

- When thermal wire gets red color (after $1.5 \mathrm{~s}$ ) or when smell PMMA burn, open the GO2 line by solenoid valve command (ON). The contact-burning surface is melted and evaporated due to emission of thermal heat from wire. Reaction of vapors with injected oxygen results in starting of ignition and subsequent combustion. That method showed longer delay ignition time (about $2.0 \mathrm{~s}$ ).

Figure (15) describes the profile of pressure and temperature with time for the case of using thermal wire tool with PMMA and $\mathrm{GO}_{2}$.

The thermal wire starts to generate thermal energy to melt the solid surface and ignition is started slowly. Steady state combustion is reach after $2.5 \mathrm{~s}$. The thermocouple at preheating chamber reached a maximum temperature of $800{ }^{\circ} \mathrm{C}$. 


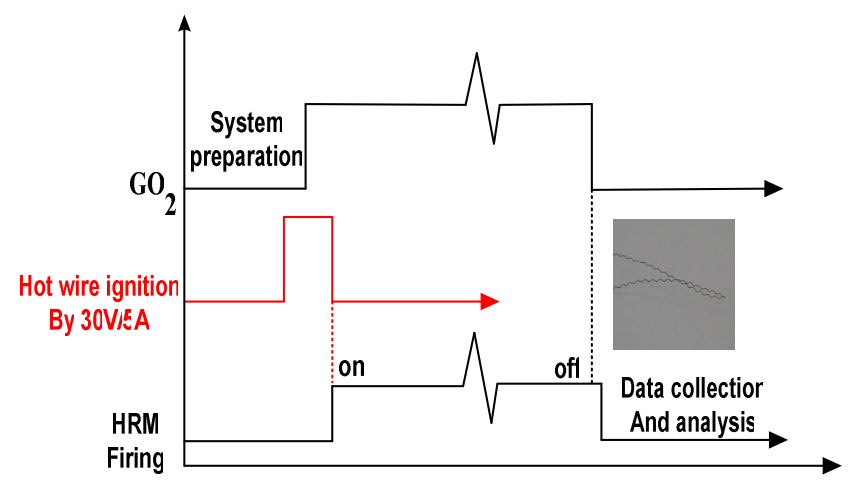

Fig. (14) Thermal Wire Tool Ignition Procedure.

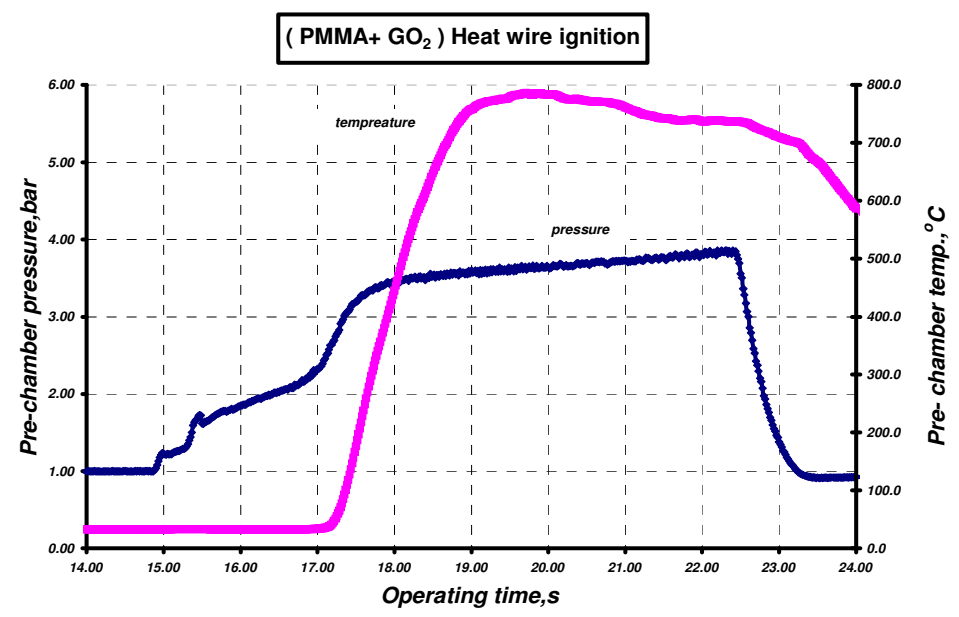

Fig. (15) Ignition by Heat Wire.

\section{Heat Exchanger (Hot Air Ignition)}

The final investigated ignition method was accomplished by injecting the $\mathrm{GO}_{2}$ with high temperature through PE fuel port. $\mathrm{GO}_{2}$ should reach a temperature higher than the melting point of solid fuel. Heat exchanger with $2000 \mathrm{~W}$ thermal coil was used. The procedure to start ignition is described in Figure (16)

- Adjust feed system.

- Passing 220-volt AC through thermal coil of heat exchanger.

- When thermocouple indicates measured temperature about $200{ }^{\circ} \mathrm{C}$ (after about 5 min), turn off 220-volt AC current supply.

- Open the GO2 line by switching on solenoid valve command (ON).The injected hot GO2 through fuel grain port causes grain surface to melting, evaporate. Complete is reached after ignition delay time (about $1.7 \mathrm{~s}$ ).

However, a longer delay time compared to other ignition systems was noticed. The method is believed to be very suitable for laboratory SSHRM. The ignitions get easily with small port diameter with short delay time. 
Figure (17) describe a sample of the profile of pressure and temperature with time for the case using heat exchanger tool with PE and GO2. The delay ignition time can be reduced when increasing heat exchanger start temperature up to more than $200^{\circ} \mathrm{C}$.

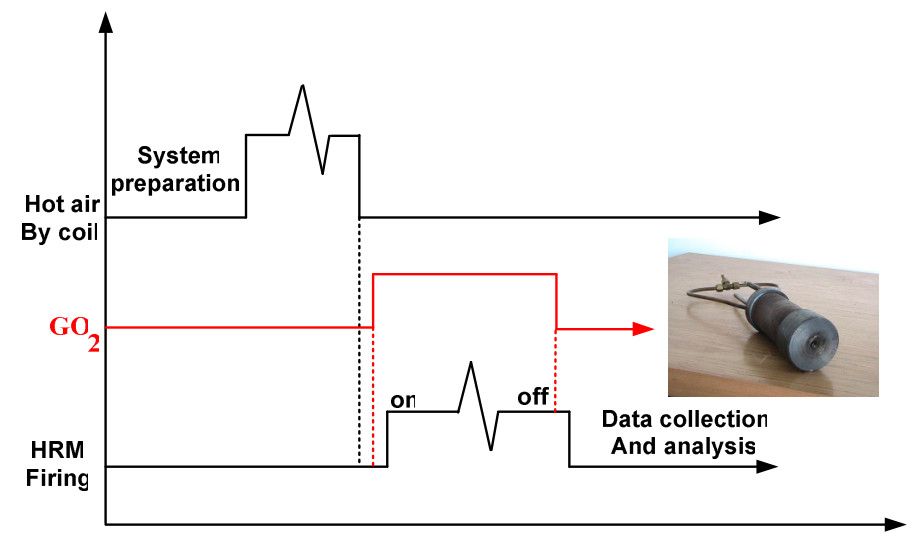

Fig. (16) Heat Exchanger Tool Ignition Procedure.

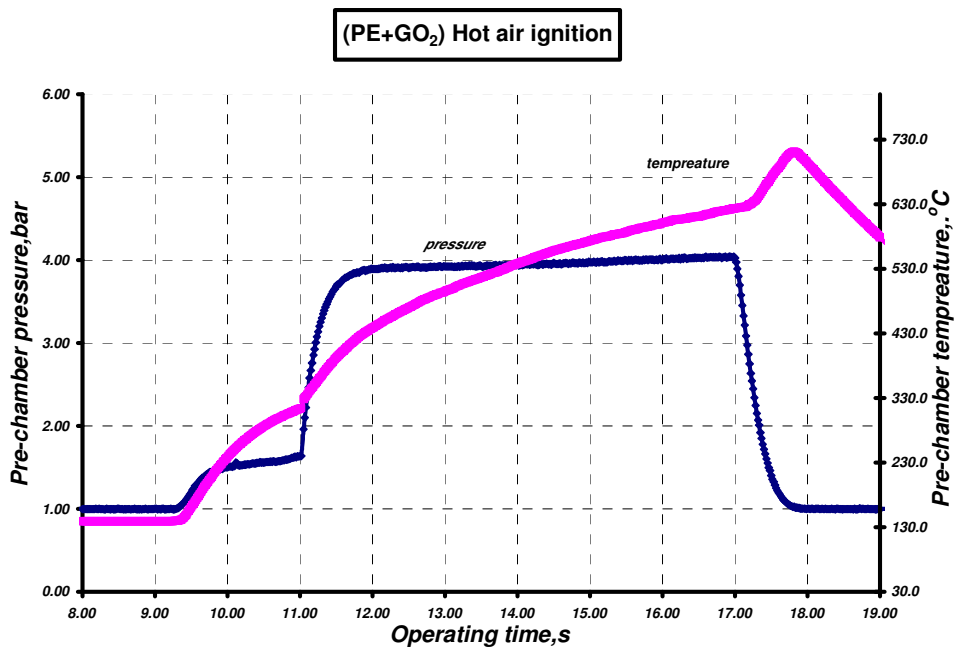

Fig. (17) Ignition by Hot Air.

\section{RE-START OPERATION}

The capability of reliable re-start of hybrid propulsion is one of its principal operational advantages over the solid propulsion. The on-off maneuver could easily be done with HRM. Re-start of hybrid motor is identical to the initial start-up; the only difference is the initial size of the port that would change the initial mixture ratio.

No specific problems were noted with re-start of tested hybrid motor. In fact, because the start/re-start sequence is relatively close in time (less than $5 \mathrm{~s}$ ) the fuel grain channel, oxidizer injection head and nozzle part are still quite warm, resulting to faster re-start than the initial start-up.

Re-start capability is demonstrated during test as shown in Figure (18). On-off valve (solenoid type) was used in oxidizer line to control of oxidizer; this valve is operated 
from the control room through current connection. The ignition delay is shown to be less than $0.5 \mathrm{sec}$. It decreases with smaller port diameter and higher Al\%.

Using heat exchanger with gaseous oxidizer allows easy start/ re-start operation, since oxidizer high temperature leads to spontaneous ignition with fuel grain surface. The thrust modulation is one of the main attractive features of hybrid propulsion. It could be carried out more easily than other propulsion systems, since varying only the oxidizer mass flow rate could control the chamber pressure, which results into thrust variation.

The ignition and re-startable operation can be improved by increasing pre-heating of the heat exchanger and fuel grain material.

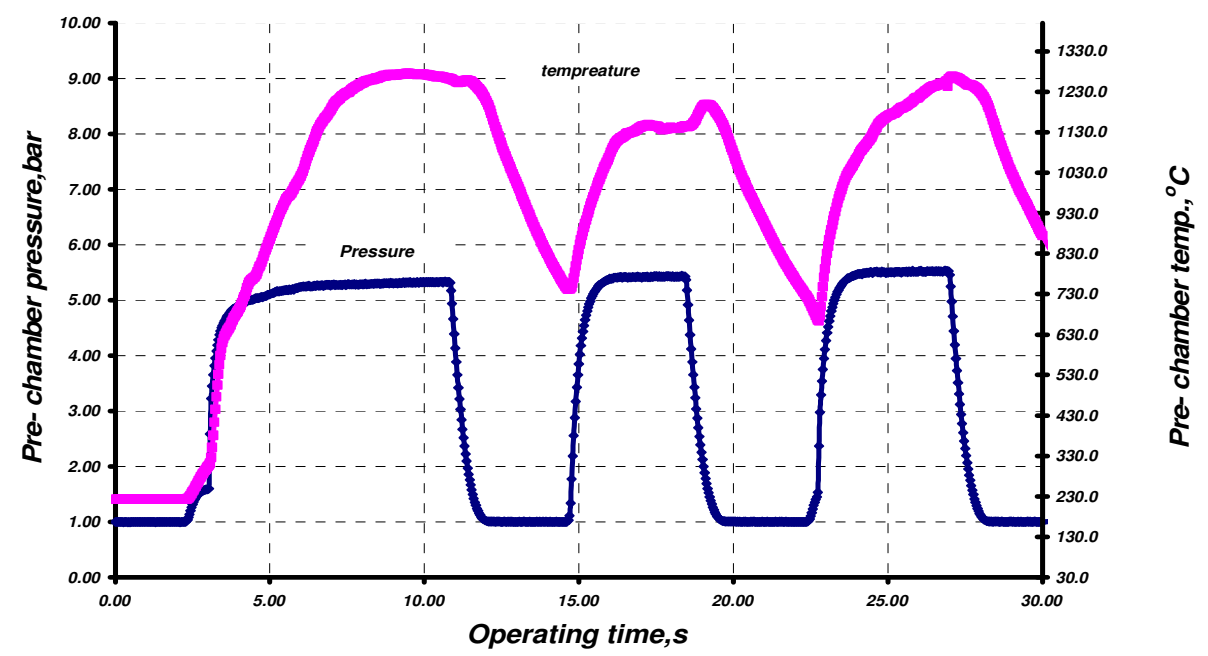

Fig. (18) Re-Start Operation of Hybrid Rocket Motor.

\section{EVALUATION AND DISCUSSIONS}

Table (4) summarized the delay times for different studied ignition methods. For subsequent experimental work, the method heat exchanger was applied for ignition of SSHRM's in the course of static firing. The method was selected for the approved high reliability, safety and low cost.

Ignition lags from several hundred milliseconds down to tens of microseconds have been observed with chemical propulsion systems. Various techniques have been employed to decrease the ignition lag. In general, it is advantageous to minimize ignition lags in order to obtain higher reliability and repeatability and to prevent ignition pressure spikes.

Table (4) Summary of Delay Times for Different Ignition Methods.

\begin{tabular}{|l|l|}
\hline Method of ignition & Delay time(s) \\
\hline Pyrotechnic charge & Less than $0.4 \mathrm{~s}$ \\
\hline Fuse wire & Less than $0.75 \mathrm{~s}$ \\
\hline Heater wire & About $2 \mathrm{~s}$ \\
\hline Heat exchanger & $1.7 \mathrm{~s}$ \\
\hline
\end{tabular}


The ignition process, both initially and in restart operations, is probably one of the least understood phenomena in hybrid combustion. Many design variables appear to affect the ignition process. Currently many questions remain partially or fully unanswered. For example, what is the best way to distribute the ignition energy and/or the oxidizer flow over the hybrid grain (uniformly, head end, in valley, on plateaus, etc.)? The ignition energy can also be distributed in various forms gases, solid-liquid interaction, etc. What is the optimum amount of ignition energy consistent with the propellant formulation, $\mathrm{G}_{\mathrm{ox}}$ can the hybrids tolerate over ignition? What actually causes the ignition? What is the optimum time between ignition and oxidizer flow initiation? Will addition of solid oxidizer to the solid grain insure greater ignition reliability and less ignition lag? There are some of the problems, which must be considered. There is an obvious need for basic studies in ignition, which would hopefully lead to at least a qualitative for the hybrid ignition process.

When restart capability is required, heat soak into the solid grain between firings must be considered. Ignition at low $\mathrm{G}_{\mathrm{ox}}$ may also be expected to produce undesirably long ignition delays.

\section{CONCLUSION}

The objective of the present work is to study the design parameters and re-stat phenomena of the laboratory SSHRM and selection of a safe and suitable ignition method.

A small scale HRM has been designed, manufactured and used with different initial port diameter of fuel grain $(5,20$ and $28 \mathrm{~mm})$ and different Al powder percent $(2.5$, $5.0,7.5,10.0,12.5$, and $15.0 \%$ ). The used propellant was PMMA and PE in the form of a tubular grain as fuel and gas oxygen as oxidizer, both selected for reasons of availability and safety.

The first phase of the study is devoted to confirm SSHRM design parameters and study the ignition method for laboratory HPS. Results can be summarized as follows:

- PMMA fuel grain material with low cost, high safety and transparency is preferred to study and demonstrate ignition phenomena where the combustion flame is visible.

- PE is chosen as a solid fuel for performing the experimental work, thanks to its good machinability, low cost, acceptable performance, availability in many forms and environmentally safe combustion products.

- The selection of oxygen as oxidizer is based on quality of handling, storability, transportability, ignition, toxicity, and other parameters.

- Choice Al powder as energetic material is based on its thermal properties, ease of processing, and relatively low cost.

- Ignition by pyrotechnic (squib) is not secured and has limited time of storage, while fuse and thermal wires have longer delay time (more than $2 \mathrm{sec}$ ) and are less reliable at high oxidizer mass flux. 
- Ignition by hot air proved to be a very attractive ignition method for small port fuel diameter (less than $20 \mathrm{~mm}$ ), for its higher safety, higher reliability and acceptable delay time (less than $1.7 \mathrm{~s}$.).

- Observations of the fuel grain active channels before and after firings reveals that, the remaining fuel port surface is relatively smooth with black carbon traces and slight inflating near the injection head. This is better demonstrated with small initial port $(5 \mathrm{~mm})$.

Adding Al powder to PE fuel proved to have the following impact on performance:

- More smooth fuel grain surface and less soot have been observed when using Al.

- Higher regression rate and combustion efficiency are significant at Al powder additive.

- Decreased nozzle life and ignition delay time.

- Reduced emissions of product gases (soot, unburned hydrocarbons).

The re-start operation was demonstrated several times and can be carried out more easily with hot air ignition method.

\section{REFERENCES}

[1] Humble, R., Henry, Gary, N.and Larson, Wiley, J., "Propulsion System Analysis and Design," United States Air Force Academy, 1995.

[2] Web page (http://www.purdue.edu/).

[3] Web page (http://www.stanford.edu/).

[4] Lengelle, G., "Hybrid Propulsion, Historical Aspect. Context. International Activities," Energetic Dept., ONERA, France, Jan. 2003.

[5] Web page (http://www.global-defence.com/2003/TnoPrins_profile.htm).

[6] Selph, C, "Computer Program For calculation of Complex Chemical Equilibrium Composition" NASA SP-273, United States Air force Academy, version, July 1994

[7] Wooldrige, C.E, and muzzy, R.J, "Internal Ballistic Considerations in Hybrid Rocket Design", j.Spacecraft Vol.4, No.2, Feb.1967. 